\title{
FGFR3 NM_000142.4:C.1118A>G
}

National Cancer Institute

\section{Source}

National Cancer Institute. FGFR3 NM 000142.4:C.1118A>G. NCI Thesaurus. Code

C128910.

A nucleotide substitution at position 1118 of the coding sequence of the FGFR3 gene where adenine has been mutated to guanine. 